\title{
The Effects of Long Term Sleep and Exercise Deprivation on Total Serum Testosterone in Male Professional Drivers
}

\author{
Ghulam Nabi (Corresponding author) \\ Department Animal sciences, Laboratory, Reproductive neuro-endocrinology, \\ Quaid-i-Azam University, Pakistan
}

Tel: 92-345-811-2741Ｅ-mail: ghulamnabiqau@gmail.com

Muhammad Amin

Department of Zoology, University of Karachi, Pakistan

Tel: 92-315-902-0833 E-mail: aminmuhammad013@yahoo.com

Amjad Khan

Department Animal sciences, Quaid-i-Azam University, Pakistan

Tel: 92-3329744605 E-mail:amjadkhanqau@gmail.com

Rahim Ullah

Department Animal sciences, Quaid-i-Azam University, Pakistan

Tel: 92-301-835-054 E-mail: rukazqau@ gmail.com

Muhammad Shuaib

Department Animal sciences, Quaid-i-Azam University, Pakistan

Tel: 92-343-977-2779 E-mail: shuaibgeneticist@ gmail.com

Ayaz Ali khan

Department of Biotechnology, University of Malakand, Chakdara

Dir Lower, Khyber pakhtunkhwa, Pakistan 
Tel: 92-345-5886-0677 E-mail: lalatejan@gmail.com

Received: February 7, 2014 Accepted: February 24, 2014

doi:10.5296/jbls.v5i2.5073 URL: http://dx.doi.org/10.5296/jbls.v5i2.5073

\begin{abstract}
The aim of the present study was to find out the effects of long term sleep deprivation and lack of exercise on total serum testosterone level and their consequences in male professional drivers.

This study was conducted at Mingora and Timergara in District Swat and District Dir respectively, Khyber Pakhtunkhwa, Pakistan. Blood samples were taken from 50 sleep deprived sluggish drivers and from 50 normal people of the same locality. A standard format questionnaire was designed regarding their age, marital status, number of children, mating frequency, duration and timing of sleep and habit of exercise. Bio-check (USA) kit was used according to the manufacturer protocol.

The mean and standard deviation of total serum testosterone in control was $650 \pm 110 \mathrm{ng} / \mathrm{dl}$ (P $<0.0001)$, and in drivers was $410 \pm 33 \mathrm{ng} / \mathrm{dl}(\mathrm{P}<0.0001)$. Total serum testosterone level was significantly lower in sleep deprived and sluggish drivers as compared to control group. The ill effects like reduce sexual desire, erectile dysfunction, Absent morning erection, scare pubic hairs, decrease frequency for shaving, muscle weakness, fatigue, depression and poor memory were also reported from the drivers during blood sampling, but no such problems were found in the control group.
\end{abstract}

Sleep deprivation especially REM and lack of exercise has a negative effect on total serum testosterone level. This low testosterone level in turn produces ill effects both on sexual and general body health.

Keywords: Fatigue, Erection, Pubic.

\title{
1. Introduction
}

In industrialized countries the duration of sleep has been considerably decreased during last decades. Sleep is very crucial for skeletal muscles and other physiologies. Chronic sleep deprivation has serious consequences such as producing muscle atrophy by increasing glucocorticoids and decreasing testosterone, growth hormone and insulin-like growth factor-I. It is also a risk factor for the chronic diseases such as cardiovascular diseases, metabolic syndromes, cancer and hormonal imbalance. However by performing resistance exercises the level of testosterone, growth hormone and insulin-like growth factor-I can be slightly raised (Monico et al., 2013). It has been found that sleep deprived people are in stress condition and this causes hormonal imbalance by secreting more cortisol, thyroid and less Testosterone, dehydroepiandrosterone- sulphate and insulin like growth factor-1 levels. Sleep has a direct 
modulatory influence on the activity of Hypothalmo Pituitary Adrenal (HPA) axis and other hormonal axes. Sleep deprivation is an example of stressor and has serious consequences depending upon its duration (Maggio et al., 2013). Experiment resulted that sleep deprivation affects the pituitary-gonadal and pituitary- thyroidal axis by lowering the level of testosterone, prolactin and raising the level of Thyroid Stimulating Hormone (TSH), Free Tri-iodothyronine (FT3), and Free Thyroxin (FT4) as compared to control group (Jauch et al., 2013). Those fathers who sleep with their children at night and provide care to their children have low morning testosterone level as compared to those fathers who do not sleep at night with their children and do not provide care. This difference in morning testosterone occurs because the co-sleeper fathers have a disturbed sleep because of their children (Gettler, 2012). The drivers were also exposed to marijuana and cigarette smoke. Both of these inhibit secretion of Gonadotropin releasing hormone, thus significantly reducing secretion of testosterone (Murphy et al., 1998; Briggs et al., 1973; Shaarawy et al., 1982). Different types of exercise of moderate-intensity may reduce age-related physiological dysfunction associated with inflammation and oxidative stress by increasing expression and activity of the Nuclear factor erythroid 2-Related Factor (NRF2), a transcriptional regulator of the cellular anti-oxidant system which ultimately leads to high testosterone level in serum (Zhao et al., 2013). It has been concluded that strength training even in aging men slightly increases testosterone resulting in increased muscle function (Kvorning et al., 2013). Even in trained eu-menorrheic women short-term elevations in testosterone can be induced by prolonged aerobic exercise. This increase may result from either increased androgen production and/or decreased degradation rates of the hormone, and are not solely the result of plasma fluid shifts from the exercise (O'Leary et al., 2013). Low testosterone level in the body for long time due to either reason can causes cardiovascular problems, insulin resistance, obesity, osteoporosis, erectile dysfunction, hypoactive sexual desire, reduced nocturnal and morning erection, fatigue and depression (Buvat et al., 2013)

In the present study sleep deprived sluggish drivers and healthy peoples were selected. In such drivers there is lack of qualitative and quantitative sleep either due to poverty or illiteracy. In their short sleep the drivers wake up several times due to noise, brake etc. so in such drivers all the sleep stages are not achieved especially the REM (Rapid Eye Movement) which is crucial for testosterone secretion. Morning blood samples were taken from the sleep deprived and exercise deficient professional drivers and from people who take 8 hours sleep and regular exercise. The objective of the study was to find the effects of sleep deprivation (REM) and lack of exercise on morning serum total testosterone level and theirs resulting ill effects.

\section{Materials and Methods}

\subsection{Questionnaire}

For the present study a standard format questionnaire was designed for collecting particular information from the sleep deprived and exercise deficient drivers and from the control people regarding their age, marital status, number of children, mating frequency, duration and timing of sleep and habit of exercise (Table 1).

\subsection{Data Collection}




\section{Macrothink}

During sampling, 100 (50 sleep deprived and exercise deficient drivers and 50 controls) male Individuals were selected. Before taking interviews and blood sampling a written consent was signed from all the individuals. The morning blood samples from the drivers and control were collected in Mingora and Timergara, at district Swat and Dir (Lower), Khyber Pakhtunkhwa, Pakistan, from 14 August 2013 to 28 August 2013.

\subsection{Blood Sampling from Sleep Deprived and Exercise Deficient Drivers}

$5 \mathrm{ml}$ of the blood was taken from the brachial vein aseptically through a health technician and were immediately transferred into glass Vacutainer tubes (Becton Dickinson) without anticoagulant or preservative. These blood samples were taken from 9:00 AM to 10:00 AM after breakfast. Samples were transferred on dry ice to laboratory for immediate analysis. Serum was obtained after centrifugation at $3200 \mathrm{rpm}$ at $4^{\circ} \mathrm{C}$. Serums were stored at $-20^{\circ} \mathrm{C}$ for later analysis. Total serum testosterone was measured using testosterone enzyme immunoassay test kit, Bio-check (USA) according to the manufacturer protocol.

\subsection{Blood Sampling from Control}

The people living around the bus stations in the same area were taken as control. A total of 50 people were randomly selected from the given areas. For the collection and analysis of blood samples same procedure was adopted as for drivers. The individuals selected were physically normal, have no history of chronic diseases, addiction and were not using any medications.

Statistical analysis

The results obtained were statistically analyzed by using Graphpad Prism, Demo version 05 (www.graphpad.com). The results were represented through mean and standard deviation and the comparison between two groups was performed by using student T-test. P value $<0.05$ was considered to be statistically significant.

\section{Results}

\subsection{History of Drivers and Control}

Two groups were made, control and drivers. Each group was then divided into 3 age groups ranging from 25 to 55 years. Specific information from both control and drivers were collected via a standard questionnaire from various age groups and are summarized in Table 1.

Table 1. History of drivers and control

\begin{tabular}{|c|c|c|c|c|c|c|c|}
\hline $\begin{array}{l}\text { Age } \\
\text { Group } \\
\text { (Years) }\end{array}$ & $\begin{array}{l}\text { Years } \\
\text { after } \\
\text { marriage }\end{array}$ & $\begin{array}{l}\text { children } \\
\text { number } \\
\text { (average) }\end{array}$ & $\begin{array}{l}\text { Mating } \\
\text { frequency } \\
\text { (average/week) }\end{array}$ & $\begin{array}{l}\text { Sleep } \\
\text { duration } \\
\text { (hours) }\end{array}$ & $\begin{array}{l}\text { Sleep } \\
\text { timing }\end{array}$ & $\begin{array}{l}\text { Exercise } \\
\text { (average) }\end{array}$ & Health Problems \\
\hline $\begin{array}{l}\text { Drivers } \\
25-34 \\
(n=15)\end{array}$ & $10-15$ & 02 & 03 & $3-4$ & Variable & Absent & $\begin{array}{l}05=\text { absent } \\
\text { morning } \\
\text { erection } \\
10=\text { reduce libido }\end{array}$ \\
\hline $35-44$ & & & & & & & $\begin{array}{l}10=\text { absent } \\
\text { erection, reduce }\end{array}$ \\
\hline
\end{tabular}




\begin{tabular}{|c|c|c|c|c|c|c|c|}
\hline$(n=20)$ & $15-20$ & 03 & 02 & $2-3$ & Variable & Absent & $\begin{array}{l}\text { libido } \\
10=\text { muscle } \\
\text { weakness, } \\
\text { erection problem, } \\
\text { fatigue }\end{array}$ \\
\hline $\begin{array}{l}45-55 \\
(n=15)\end{array}$ & $20-25$ & 03 & 01 & $2-3$ & Variable & Absent & $\begin{array}{l}10=\text { absent } \\
\text { morning erection, } \\
\text { reduce libido, } \\
\text { memory loss, low } \\
\text { pubic hairs, } \\
\text { fatigue } \\
05=\text { depression, } \\
\text { poor memory, } \\
\text { low libido, reduce } \\
\text { shaving } \\
\text { frequency. }\end{array}$ \\
\hline $\begin{array}{l}\text { Control } \\
25-34 \\
(n=15)\end{array}$ & $10-15$ & 04 & 05 & $7-8$ & Specific & 02 hrs. & No specific \\
\hline $\begin{array}{l}35-44 \\
(n=20)\end{array}$ & $15-20$ & 05 & 03 & $6-7$ & Specific & 02 hrs. & $02=$ hypertension \\
\hline $\begin{array}{l}45-55 \\
(n=15)\end{array}$ & $20-25$ & 06 & 02 & 6 & Specific & $01 \mathrm{hrs}$. & $\begin{array}{l}03=\text { hypertension } \\
01=\text { Diabetes } \\
02=\text { fatigue }\end{array}$ \\
\hline
\end{tabular}

SD*= Standard Deviation, C.I* $=$ Confidence Interval

\section{Discussion}

In the present study we analyzed the ill effects of disturb short sleep and lack of exercise in drivers on testosterone level. Some long traveling buses have two drivers, one sleep while other drive. The sleeping drivers were expose to noise, brake and other irritating factors as a result they awake several times. They also failed to complete all stages of sleep especially REM stage which is either totally absent or very brief. REM sleep is very important for testosterone secretion. Testosterone maintains our general as well as sexual health. Sleep deprivation and sluggishness is a common phenomenon in both industrialized and developing countries and produces ill effects on general and sexual health. In the developing countries like Pakistan, particularly in Khyber Pakhtunkhwa the awareness about this problem is lacking.

Sleep is a very active, dynamic, complex behavior and occupies one-third of human life span. Sleep modulates cardiovascular, endocrine and metabolic system. Over the last several decades the average sleep duration has decreased. Long term sleep deprivation is a risk factor for several outcomes such as; disturb testosterone level, sexual dysfunction, Type-2 diabetes, insulin resistance and weight gain. In young men testosterone level rises during daytime sleep 
just as in night time sleep, but the levels fall upon waking thus confirming that sleep, rather than a circadian rhythm is critical for testosterone regulation. The level of testosterone begins to rise with the onset of sleep and reaches to a peak at REM sleep onset approximately 90 min later. It has also been found that testosterone levels were highest during the first REM sleep episode and lowest when the subjects were awake. Sleep disturbance can cause both lower and higher circulating testosterone level. Men who sleep less than 4 hours and those who sleep 4-6 hours daily had significantly lower androgen concentrations than those who slept over 8 hours (Monica et al., 2011).

The fragmented sleep and short time spent in REM sleep causes a significant decline in serum total testosterone concentration. After awakening testosterone decline exponentially so old peoples who wake up many times have lower testosterone, which leads to erectile dysfunction, ejaculatory problems, diminished libido etc. (Monica et al., 2010; Penev., 2007). Rafael et al., 2001 found that sleep associated rise in testosterone is associated with the appearance of first REM sleep. Individuals with fragmented sleep and partial sleep deprivation having no REM sleep have a significantly low testosterone level. These findings are in agreements with our results because drivers are partially sleep deprived and have nearly no REM sleeps.

Figa et al, 1996 compared the control group with drivers and found that not only salivary testosterone level was reduced but sperm quality (i.e., sperm concentration, sperm morphology, and motility) was also compromised. They considered urban automobile driving a stressful work activity which negatively affects endocrine function and thus is a risk factor for male fertility. Rafael et al, 1999 compared testosterone level in waking, first NREM (Non Rapid Eye Movement) and REM sleep and found that testosterone level were significantly lower when the individuals were awake and were significantly higher during the first REM. Similarly serum testosterones were significantly higher during the first REM as compared to the pre- REM period. Raul et al, 1992 found that sleep related disordered, REM sleep and sleep efficiency has association with testosterone. Decreased sleep efficiency and number of REM episodes while increased in latency to the onset of REM are associated with low androgen level, and this association is independent of age.

Chronic sleep deprivation produces serious health effects by increasing the level of glucocorticoids, cortisol, TSH (Thyroid Stimulating Hormone), Free Tri-iodothyronine (FT3), Free Thyroxin (FT4) and decreasing the level of testosterone, dehydroepiandrosterone-sulphate, growth hormone and insulin like growth factor-1. Such study is an agreement with our findings (Monico et al., 2013; Maggio et al., 2013; Jauch et al., 2013; Gettler, 2012).

In a series of experiments in normal young adult men the interrelations of plasma LH (Luteinizing Hormone), FSH (Follicle Stimulating Hormone), prolactin (PRL), and testosterone during sleep were measured. It was found that during night baseline LH and FSH concentrations did not change, whereas PRL and testosterone over the course of night did show similar patterns of increasing concentration. In summer season due to shorter sleep duration, testosterone concentration was reported to be lowered. But in Ramadan sleep onset is later, sleep duration is reduced and it did not change the 24-h mean concentration of testosterone, but 
did delay the onset of the increase. After 4 days of sleep deprivation in male rats, decreased testosterone levels and increased levels of progesterone, PRL, corticosterone, and catecholamines were observed. During military operations there is prolong psychological and physical stress, sleep deprivation lasts for several days and androgen levels fall by $70-90 \%$ (Monica et al., 2008). Long term low testosterone has serious consequences and can causes decreased libido, osteoporosis, depression, obesity, muscle weakness, fatigue, errection problems and disturb secondary sex characters (Ranjan et al., 2010). Same findings were reported during our study.

Children with better sleep quality were associated with better control over aggressive behaviors, while sleep deprived display aggression. Researchers had found that REM deprived rats engaged in more aggressive behavior (Kimberly et al., 2013).

In addition to sleep the drivers were also exposed to cigarette and marijuana smoke. It is well reported that nicotinic cigarette smoke and cocaine both stimulate the mesolimbic dopamine system that elevated the concentration of extracellular dopamine (Kuhar et al., 1991; Corrigall et al., 1992; Di Chiara , 2000; Watkins et al., 2000). This dopamine negatively regulates GnRH (Gonadotropin Releasing Hormone) secretion which causes significant reduction in testosterone level, affecting sexual health (Murphy et al., 1998; Briggs et al., 1973; Shaarawy et al., 1982). Marijuana activates dopamine and opioid which inhibit GnRH secretion, thus negatively affecting our sexual health (Murphy et al., 1998).

Exercise, competitions and resistance training transiently increase testosterone concentration in men and women. Testosterone levels vary before and after competition. Moderate intensity exercise raises the level of serum testosterone even in aging men and eu-menorrheic women (Zhao et al., 2013; O'Leary et al., 2013; Ruth et al., 2012). Testosterone concentration increases significantly after exercise. Therefore coaches may consider low-intensity resistance exercise as a potential training method for athletes who need to maintain muscle mass and strength during the long in-season (Con et al., 2012).

\section{Conclusion}

In conclusion it was observed that in professional drivers due to increased work load (because of poverty or illiteracy) there is lack of sleep and proper exercise which produce a stress condition in their bodies. This stress may be then responsible for low serum total testosterone level. Low testosterone has ill effects on general and sexual health. Therefore these peoples should take enough qualitative and quantitative sleep and exercise to maintain normal serum testosterone concentration and thus general and sexual health. They are also advised to take a resistance exercise that raises testosterone level.

\section{Limitations}

Due to limited facilities the correlation with other hormones was not studied.

\section{References}

Briggs, MH. (1973). Cigarette smoking and infertility in men. Medical Journal of Australia. 1, 616-617. 
Buvat, J. Maggi, M. Guay, A., \& Torres, L. (2013). Testosterone deficiency in men: Systematic review and standard operating procedures for diagnosis and treatment. Journal of sexual medicine Sex Med. 10, 245-284. http://dx.doi.org/10.1111/j.1743-6109.2012.02783.x

Con, M. Ikeda, T. Homma, T., \& Suzuki, Y. (2012). Effects of Low-Intensity Resistance Exercise under Acute Systemic Hypoxia on Hormonal Responses. Journal of Strength and Conditioning Research. 26, 611-617.

Corrigall, WA. Franklin, KB. Coen, KM., \& Clarke, PB. (1992). the mesolimbic dopamine system is implicated in the reinforcing effects of nicotine. Psychopharmacology.107, 285-289. http://dx.doi.org/10.1007/BF02245149

Di, CG. (2000) Role of dopamine in the behavioral actions of nicotine related to addiction. European Journal of Pharmacology. 393, 295-314. http://dx.doi.org/10.1016/S0014-2999(00)00122-9

Figa, T. Cini, C. Varricchio, D., \& Lenzi, A. (1996). Effects of Prolonged Auto vehicle driving on male reproductive Function: A Study among taxi drivers. American Journal of Industrial Medicine. 30 , 750-758. http://dx.doi.org/10.1002/(SICI)1097-0274(199612)30:6<750::AID-AJIM12>3.0.CO;2-1

Gettler, LT. (2012). Does Cosleeping Contribute to Lower Testosterone Levels in Fathers? Evidence from the Philippines. Public library of science. 7, 41559.

Jauch, K. Schmid, SM. Hallschmid, M. Oltmanns, KM., \& Schultes, B. (2013). pituitarygonadal and pituitary- thyroidal axis hormone concentration before and during a hypoglycemic clamp after sleep deprivation in healthy men. Public library of science 8, 54209.

Kimberly, A. Cheryl, M. Shawn, NG. Ryan, PR., \& Stacey, DM. (2013). Sleep Deprivation lowers reactive aggression and testosterone in men. Biopsychology. 92, 249-256.

Kuhar, MJ. Ritz, MC., \& Boja, JW. (1991). the dopamine hypothesis of the reinforcing properties of cocaine. Trends in Neurosciences. 14, 299-302. http://dx.doi.org/10.1016/0166-2236(91)90141-G

Kvorning, T. Christensen, LL. Madsen, K. Nielsen, JL. Gejl, KD. Brixen, K. (2013). Mechanical muscle function and lean body mass during supervised strength training and testosterone therapy in aging menwith Low-normal testosterone levels. Journal of the American Geriatric Society. 61, 957-62. http://dx.doi.org/10.1111/jgs.12279

Maggio, M. Colizzi, E. Fisichella, A. Valenti, G. Ceresini, G. Dall'Aglio, E. (2013). Stress hormone, Sleep deprivation and cognition in older adults. Maturitas. 76, 22-44. http://dx.doi.org/10.1016/j.maturitas.2013.06.006

Monica, A. Tathiana, A. Renata, M. Helena, H., \& Sergio, T. (2011). The association of Testosterone, sleep, and sexual function in men and women. Brain Research. 1416, 80-104. http://dx.doi.org/10.1016/j.brainres.2011.07.060

Monica, L. Sergio, T. (2008). The effects of testosterone on sleep and sleep- disordered 
Breathing in men: Its bidirectional interaction with erectile function. Sleep medicine review. 12 , 365-379. http://dx.doi.org/10.1016/j.smrv.2007.12.003

Monica, LA. Rogerio, SS. Lia, RA. Bittencourt, ST. (2010). Prevalence of erectile dysfunction complaints associated with sleep disturbances in Sao Paulo, Brazil: A population-based survey. Sleep Medicine.11, 1019-1024. http://dx.doi.org/10.1016/j.sleep.2009.08.016

Mônico, MN. Antunes, HK. Dattilo, M. Medeiros, A. Souza, HS., \& Lee, KS. (2013). Resistance exercise: A non-pharmacological strategy to minimize or reverse sleep deprivation-induced muscle atrophy. Medical Hypotheses. 80, 701-705. http://dx.doi.org/10.1016/j.mehy.2013.02.013

Murphy, LL. Munoz, RM. Adrian, BA. Villanu, MA. (1998). Function of cannabinoid receptors in the neuroendocrine regulation of hormone secretion. Neurobiology. 5, 432-446.

O'Leary, C. B., Lehman, C., Koltun, K., Smith, Ryan. A., Hackney, A. C. (2013). Response of testosterone to prolonged aerobic exercise during different phases of the menstrual cycle. $\begin{array}{llll}\text { Eureopean Journal of Applied Physiology. 9, 2419-24. } & \text { 9, }\end{array}$ http://dx.doi.org/10.1007/s00421-013-2680-1

Penev, P. (2007). Association between sleep and morning testosterone levels in older men. Sleep.30, 427-432.

Rafael, L. Paula, H. Michal, L. Zila, S., \& Peretz, L. (1999). Relationship between rapid eye movement sleep and testosterone secretion in normal men. Journal of Andrology. 20, $731-737$

Rafael, L. Ziva, Z. Zill, O. Paula, H., \& Peretz, L. (2001). Disruption of the Nocturnal Testosterone Rhythm by Sleep Fragmentation in Normal Men. The journal of clinical endocrinology and metabolism.86, 3.

Ranjan, A. Mohan, A., \& Shaun, R. (2010). Androgen deficiency in the aging man. Australian Family Physician. 39, 10.

Raul, CS. Daniel, W., \& John, M. (1992). Pituitary- Gonadal function during sleep in healthy aging men. Psych neuroendocrinology.17, 6, 599-609.

Ruth, IW. Steven, JS. (2012). Testosterone and sport: Current perspectives. Hormone and behaviour. 61, 147-155. http://dx.doi.org/10.1016/j.yhbeh.2011.09.010

Shaarawy, M. Mahmoud, KZ. (1982). Endocrine profile and semen characteristics in male smokers. Fertility and Sterility. 38, 255-257.

Watkins, SS. Koob, GF., \& Markou, A. (2000). neural mechanisms underlying nicotine addiction: acute positive reinforcement and withdrawal. Nicotine and Tobacco Research.. 2, 19-37. http://dx.doi.org/10.1080/14622200050011277

Zhao, X. Bian, Y. Sun, Y. Li, L. Wang, L. Zhao, C. (2013). Effects of moderate exercise over different phases on age- related physiological dysfunctions in testes of SAMP8 mice. Experimental gerontology. 48, 869-80. http://dx.doi.org/10.1016/j.exger.2013.05.063 


\section{Copyright Disclaimer}

Copyright reserved by the author(s).

This article is an open-access article distributed under the terms and conditions of the Creative Commons Attribution license (http://creativecommons.org/licenses/by/3.0/). 